\title{
Micro RNA Expression and Prognosis in Low-grade Non- invasive Urothelial Carcinoma
}

Nelson Dip, Sabrina T. Reis, Daniel K. Abe, Nayara I. Viana, Denis R. Morais, Caio M. Moura, Betina Katz, Iran A. Silva, Miguel Srougi, Katia R. M. Leite

Laboratory of Medical Investigation, Urology Department - LIM55, University of Sao Paulo Medical School, Sao Paulo, Brazil

\section{ABSTRACT}

Purpose: To analyze a possible correlation between a miRNA expression profile and important prognostic factors for pTa urothelial carcinomas (UC), including tumor size, multiplicity and episodes of recurrence.

Materials and Methods: Thirty low-grade non-invasive pTa bladder UC from patients submitted to transurethral resection were studied, in a mean follow-up of 17.7 months. As controls, we used normal bladder tissue from five patients submitted to retropubic prostatectomy to treat benign prostatic hyperplasia. Extraction, cDNA and amplification were performed for 14 miRNAs (miR-100, -10a, -21, -205, -let7c, -143, -145, -221, $-223,-15 a,-16,-199 a$ and -452) using specific kits, and RNU-43 and -48 were used as endogenous controls. Statistical tests were used to compare tumor size, multiplicity and episodes of recurrence with miRNAs expression profiles.

Results: There was a marginal correlation between multiplicity and miR-let7c over-expression. For all others miRNA no correlation between their expression and prognostic factors was found.

Conclusion: We did not find differences for miRNAs expression profiles associated with prognostic factors in tumor group studied. The majority of miRNAs are down-regulated, except miR-10a, over-expressed in most of cases, seeming to have increased levels in tumor with more unfavorable prognostic factors. More studies are needed in order to find a miRNA profile able to provide prognosis in pTa UC to be used in clinical practice.

\section{ARTICLE INFO}

Key words:

MicroRNAs; Urinary Bladder

Neoplasms; Prognosis;

Molecular Biology

Int Braz J Urol. 2014; 40: 644-9

Submitted for publication:

January 06, 2014

Accepted after revision:

February 07, 2014

\section{INTRODUCTION}

Bladder cancer (BC) is the second most common malignancy of the urinary tract, with 73,510 new cases estimated in 2012 and about 15,000 deaths in USA (1). Ninety percent of BC is urothelial carcinomas (UC), and they are related to exposure to environmental carcinogens and tobacco consumption. Eighty to ninety percent of tumors are papillary low-grade, non-muscle invasive that rarely progress to muscle invasion (2), whereas 10 to $20 \%$ of them are muscle invasive at diagnosis, and 50\% of patients die due to disease progression (3).

pTa low-grade UC is characterized by frequent recurrences but low progression rates (4). Although there are no specific characteristics that indubitably predict tumor behavior, some clinical, histological and molecular features have been related to tumor recurrence and 
progression. Multiplicity, tumor size and number of recurrences are related to higher recurrence rates and lower recurrence-free survival $(5,6)$. Despite optimal survival, increased recurrence rates require extended follow-up, invasive procedures and high costs to health systems (7).

There are two distinct molecular pathways underlying the main two types of UC, low-grade non-muscle invasive and high-grade muscle invasive, that are currently investigated in order to identify new potential biomarkers for diagnosis, disease monitoring, prognosis and development of new targeted therapies (8-10). The most common genetic alteration of low-grade and stage UC is an activating mutation of the fibroblast growth factor receptor 3 gene (FGFR3) $(11,12)$, whereas mutations in p53 and retinoblastoma (RB1) genes have been identified as being characteristic of high grade invasive UC carcinogenesis (12).

The FGFR3 gene belongs to growth factor receptor family related to the tyrosine kinase signaling pathway, which plays an important role in embryogenesis, development, angiogenesis, wound healing, tissue homeostasis and tumorigenesis, regulating cell proliferation, migration and apoptosis (13). Point mutations are the primary phenomenon related to FGFR3 dysfunction allowing its ligant-independent operation (14). H-RAS is the second most common oncogene associated with low-grade non-invasive UC carcinogenesis and H-RAS mutations are present in approximately 30\% of these tumors $(9,15)$. Both pathways are mutually exclusive and more than $80 \%$ of these tumors show activation of either RAS or FGFR3 genes (13).

Epigenetic events have been described in UC and are responsible for altering gene expression, mainly suppressing the activity of tumor suppressor genes. DNA methylation, histone modifications and imbalance of miRNA expression have been added to the carcinogenesis process of UC $(16,17)$. miRNAs are members of small single-stranded regulatory RNAs (19-22 nucleotides) that suppress the mRNA translation, regulating the expression of approximately one third of human genes (18). miRNAs are involved in many physiological mechanisms and have been reported as differentially expressed in several types of cancers (19-21). In UC, they can work as tumor suppres- sors, negatively controlling oncogenes as FGFR3 (miR-100) or oncomiRs acting on the control of tumor suppressor genes as p53 (miR-21) (22). The knowledge of different miRNAs expression profiles promoted an exciting discovery of diagnostic and prognostic biomarkers in oncology.

Recently we have published a work showing that miR-100 under-expression has occurred in 100\% of low-grade non-invasive pTa UC. At the same time, all cases have demonstrated strong over-expression of FGFR3. These findings could represent another mechanism related to FGFR3 carcinogenesis in addition to the point mutations (23). Now our aim is to study a possible correlation between a miRNA expression profile and the most important prognostic factors in low-grade non-invasive pTa UC, which are, multiplicity, tumor size and number of recurrence episodes.

\section{MATERIALS AND METHODS}

\section{Patients}

This study enrolled 30 low-grade non-invasive pTa UC of the bladder from patients who underwent transurethral resection as primary treatment. Twenty six (86.7\%) patients were male, the mean age was 67.3 years old, ranging from 47 to 82 . As controls, we used normal bladder tissue from five patients who underwent retropubic prostatectomy to treat benign prostatic hyperplasia. All patients of control group were male and the mean age was 66 years old, ranging from 61 to 71.There were no differences in demographic data between patients $(p=0.7)$. All patients provided informed consent and the study was approved by HCFMUSP Institutional Board of Ethics, protocol \#0176/10.

The prognostic factors studied were multiplicity, tumor size and episodes of recurrence. Multiplicity was considered positive when two or more papillary lesions in bladder urothelium were present. Regarding tumor size, we considered tumors $\leq 3 \mathrm{~cm}$ and $>3 \mathrm{~cm}$ as good and worse behavior, respectively. Episodes of recurrence were characterized as positive when there were new recurrences of the tumor beyond the first, subdivided in one or more than one episodes. The mean follow-up was 17.7 months and consisted in urine cytology and cystoscopy each three months for the first two ye- 
ars and biannually after this for three more years. New interventions were done depending on each case, disease behavior and treatment response.

For tumor and control samples, $1 \mathrm{~cm}^{3}$ of each surgical specimen was extracted and immediately snap-frozen at $-80^{\circ} \mathrm{C}$ for genetic tests, and the remaining tissue fixed in 10\% formalin routinely processed and stained with hematoxylin and eosin for histological examination to guarantee the presence of tumor in at least 75\% of the specimen (in tumor samples) or to confirm a normal urothelium (in control samples). To characterize tumor samples, histological graduation and staging followed the WHO/ISUP 2004 grading and AJCC/TNM 2010 stage, respectively.

\section{miRNA extraction and amplification}

The miRNA extraction was performed using the mirVana $\mathrm{Kit}^{\circledR}$ (Applied Biosystems, CA, USA) according to the manufacturer's instructions. miRNAs concentrations were determined by 260/280nM absorbance using a Nanodrop ${ }^{\circledR}$ ND-1000 spectrophotometer (Thermo Scientific). miRNAs cDNA were generated using a Taqman MicroRNA Reverse Transcription $\mathrm{Kit}^{\circledR}{ }^{\circledR}$ (Applied Biosystems, CA, USA) with incubation at $16^{\circ}$ $\mathrm{C}$ for $30 \mathrm{~min} ., 42^{\circ} \mathrm{C}$ for more $30 \mathrm{~min}$. and finally, $85^{\circ} \mathrm{C}$ for $5 \mathrm{~min}$. The cDNA was stored at $-20^{\circ} \mathrm{C}$ until further use. This study assessed the expression of miR-100, -10a, -21, -205, -let7c, $-125 \mathrm{~b},-143,-145,-221,-223,-15 \mathrm{a},-16-199 \mathrm{a}$ and -452, using Taqman Reagent Kits ${ }^{\circledR}$ (Applied Biosystems, CA, USA) for miRNA amplification, in a 7500 Fast Real-Time PCR System ${ }^{\circledR}$ (Applied Biosystems, CA, USA). Briefly, the samples were inserted in ABI 7500 qRT-PCR equipment and processed by $50^{\circ} \mathrm{C}$ for $2 \mathrm{~min}$., followed by $95^{\circ} \mathrm{C}$ for $10 \mathrm{~min}$ and 40 thermal cycles of $95^{\circ} \mathrm{C}$ for 15 seconds and $60^{\circ} \mathrm{C}$ for $1 \mathrm{~min}$. The reactions were conducted in duplicate, and RNU-43 and RNU48 were used as endogenous controls. Expression profiles of miRNAs were obtained by relative quantification and the final result was obtained by application of $2^{-\Delta \Delta c t}$ method. Findings greater and smaller than 1 were considerate over- and under-expressed, respectively. The number 1 in the graphics is method standardization and represents the normal controls.

\section{Statistical analysis}

For statistical purposes, we considered multiplicity (single (no) or $\geq 2$ papillary lesions (yes)), tumor size $(\leq$ or $>3 \mathrm{~cm})$ and episodes of recurrence (absent (no) or 1 and $>1$ episode (yes)) related to miRNA expression. We used Mann-Whitney U and $\mathrm{T}$ test to compare tumor size and multiplicity, and ANOVA and Kruskal-Wallis test to compare episodes of recurrence with miRNAs expression profiles. Results are presented as geometric means with a 95\% confidence interval (95\% CI), considering statistically significant a $\mathrm{p}$ value $<0.05$.

\section{RESULTS}

Twenty one (70\%) patients had multiple tumors and 7 (23.3\%) had tumors $>3 \mathrm{~cm}$. Fifteen (50\%) had multiple recurrences (mean of 2.8, ranging from 2 to 7). Two (6.7\%) patients had all the three worst prognostic criteria while four (13.3\%) had none of these unfavorable factors. Nineteen (63.3\%) patients underwent intravesical BCG under Southwest Oncology Group (SWOG) protocol (24). None of patients used mitomycin $C$ and one of them underwent radical cystectomy due to disease progression.

Table-1 presents miRNA expression features in 30 pTa UC compared to normal bladder tissue. Under-expression was found in 13 out of 14 miRNAs studied. Only miR-10a was over-expressed in 73.3\% of cases (mean of 46.38). miR-100, -125b and-205 were under-expressed in 100\% (means of $0.04,0.15$ and 0.07 , respectively), miR-143 and -223 in $96.7 \%$ (means of 0.18 and 0.49 , respectively), and miR-199a and -452 in $93.3 \%$ of the cases (means of 0.36 and 1.42, respectively).

There was a marginal correlation between multiplicity in pTa UC and miR-let7c over-expression (means of 0.03 vs. $1.46 ; p=0.07$ ). For all others miRNA there was no association between their expression and multiplicity, tumor size and number of recurrence episodes (Table-2).

\section{DISCUSSION}

It is well established that imbalance of miRNAs is an important event in human tumors, 
Table 1 - Expression profile of 14 miRNAs studied in 30 low-grade non-invasive pTa tumors. Means and medians of expression are also presented compared with normal controls.

\begin{tabular}{ccccccccccccccc}
\hline pTa $(\mathrm{n}=30)$ & 100 & $10 \mathrm{a}$ & 21 & 205 & Let7c & $125 \mathrm{~b}$ & 143 & 145 & 221 & 223 & $15 \mathrm{a}$ & 16 & $199 \mathrm{a}$ & 452 \\
\hline $\begin{array}{c}\text { Over- } \\
\text { expression (\%) }\end{array}$ & 0 & 73.3 & 26.6 & 0 & 13.3 & 0 & 3.3 & 26.7 & 20 & 3.3 & 50 & 26.7 & 6.7 & 6.7 \\
$\begin{array}{c}\text { Under- } \\
\text { expression (\%) }\end{array}$ & 100 & 26.7 & 73.4 & 100 & 86.7 & 100 & 96.7 & 73.3 & 80 & 96.7 & 50 & 73.3 & 93.3 & 93.3 \\
Mean & 0.04 & 46.38 & 1.08 & 0.07 & 1.03 & 0.15 & 0.18 & 1.61 & 1.22 & 0.49 & 2.76 & 1.47 & 0.36 & 1.42 \\
Median & 0.0008 & 4.88 & 0.4 & 0.04 & 0.02 & 0.08 & 0.009 & 0.2 & 0.3 & 0.1 & 1.04 & 0.57 & 0.13 & 0.03 \\
Min. & $8.94-13$ & 0.004 & 0.002 & 0.002 & $6.3^{-5}$ & $9.4^{-5}$ & $7.4^{-5}$ & 0.002 & 0.003 & 0.002 & 0.1 & $2.6^{-5}$ & 0.0008 & 0.0001 \\
Max. & 0.44 & 761.2 & 11.14 & 0.35 & 13.14 & 0.76 & 4.13 & 24.06 & 17,64 & 9.49 & 15.3 & 12.3 & 2.7 & 39.87 \\
\hline
\end{tabular}

Table 2 - Means of expression of the 14 miRNAs considering the prognostic factors studied in 30 low-grade non-invasive pTa samples. The values listed are presented in fold-change compared to controls.

\begin{tabular}{|c|c|c|c|c|c|c|c|c|c|c|}
\hline \multirow{3}{*}{ miRNA } & \multicolumn{3}{|c|}{ Multicentricity } & \multicolumn{3}{|c|}{ Size Tumor } & \multicolumn{4}{|c|}{ Episodes of Recurrence } \\
\hline & \multirow[t]{2}{*}{$\begin{array}{c}\text { No } \\
(n=9)\end{array}$} & \multirow[t]{2}{*}{$\begin{array}{c}\text { Yes } \\
(n=21)\end{array}$} & \multirow[t]{2}{*}{$p$} & \multirow[t]{2}{*}{$\begin{array}{c}\leq 3 \mathrm{~cm} \\
(\mathrm{n}=23)\end{array}$} & \multirow[t]{2}{*}{$\begin{array}{l}>3 \mathrm{~cm} \\
(\mathrm{n}=7)\end{array}$} & \multirow[t]{2}{*}{$\mathrm{p}$} & \multirow[t]{2}{*}{$\begin{array}{c}\text { No } \\
(n=15)\end{array}$} & \multicolumn{2}{|c|}{$\begin{array}{c}\text { Yes } \\
(n=15)\end{array}$} & \multirow[t]{2}{*}{$p$} \\
\hline & & & & & & & & $\begin{array}{c}1 \\
(n=7)\end{array}$ & $\begin{array}{c}>1 \\
(\mathrm{n}=8)\end{array}$ & \\
\hline 100 & 0.08 & 0.02 & 0.12 & 0.61 & 0.09 & 0.63 & 0.05 & 0.04 & 0.01 & 0.61 \\
\hline $10 a$ & 38.63 & 49.69 & 0.85 & 41.57 & 62.17 & 0.74 & 20.55 & 137.6 & 14.92 & 0.7 \\
\hline 21 & 0.33 & 1.41 & 0.23 & 1.35 & 0.21 & 0.24 & 0.89 & 0.26 & 2.16 & 0.26 \\
\hline 205 & 0.04 & 0.08 & 0.22 & 0.07 & 0.04 & 0.4 & 0.04 & 0.14 & 0.05 & 0.1 \\
\hline Let7c & 0.03 & 1.46 & 0.07 & 1.25 & 0.33 & 0.53 & 1.02 & 0.02 & 1.94 & 0.55 \\
\hline $125 b$ & 0.15 & 0.15 & 0.94 & 0.17 & 0.1 & 0.42 & 0.15 & 0.13 & 0.18 & 0.89 \\
\hline 143 & 0.007 & 0.26 & 0.41 & 0.22 & 0.06 & 0.63 & 0.31 & 0.21 & 0.91 & 0.67 \\
\hline 145 & 0.24 & 2.2 & 0.29 & 1 & 3.62 & 0.82 & 0.71 & 0.29 & 4.45 & 0.78 \\
\hline 221 & 1.02 & 1.3 & 0.83 & 0.56 & 3.38 & 0.56 & 1.8 & 0.72 & 0.56 & 0.63 \\
\hline 223 & 0.26 & 0.59 & 0.63 & 0.2 & 1.46 & 0.63 & 0.83 & 0.11 & 0.2 & 0.58 \\
\hline $15 a$ & 2.94 & 2.68 & 0.87 & 2.6 & 3.29 & 0.69 & 2.49 & 2.74 & 3.28 & 0.91 \\
\hline 16 & 0.57 & 1.85 & 0.25 & 1.73 & 0.62 & 0.36 & 0.97 & 0.52 & 3.23 & 0.14 \\
\hline $199 a$ & 0.24 & 0.41 & 0.47 & 0.41 & 0.19 & 0.38 & 0.4 & 0.17 & 0.43 & 0.63 \\
\hline 452 & 0.02 & 2.02 & 0.5 & 1.84 & 0.02 & 0.57 & 0.06 & 5.75 & 0.16 & 0.68 \\
\hline
\end{tabular}


including bladder cancer. Recent evidences demonstrate that miRNA can play common roles in tumorigenesis, working as tumor suppressors or oncomiRs, depending on target-genes they regulate. Except for miR-100, the choice of all miRNAs enrolled in this study was based on literature data that demonstrated key roles or promising functions in UC carcinogenic pathways. miR-100 was specifically selected for analysis because, besides being part of all research lines in our laboratory, there are limited data about its role in tumorigenic pathway of non-invasive UC.

Several studies have observed a behavior of miRNAs in cancer, and postulate this can distinguish tumor types, and separate them in different grade and stage groups $(22,25,26)$. For the first time, we have correlated a miRNA expression profile with important prognostic factors in low-grade non-invasive pTa bladder UC. This study has shown an overall miRNA under-expression profile that seems to be a hallmark of this tumor group, especially considering miR-100, -125 and -205 that were down-regulated in 100\% of cases, with means of expression very low in comparison with normal controls. Also miR-143, -223, -199a and -452 were under-expressed in $93-97 \%$ of cases, and only miR-10a has presented an over-expression in most cases. However, we did not find association between expression of these $14 \mathrm{miR}$ NAs and the main prognostic factors evaluated in low-grade non-invasive pTa UC.

miR-let7c was the only that reached a marginal significance correlating its over-expression with multiplicity ( $p=0.07$ ). This miRNA is well defined as a tumor suppressor, with a protective role against carcinogenic process. miR-let7c can control oncogene RAS and suppress its function in cellular physiological conditions (21). On the other hand, under-expression of miR-let7c could allow the RAS over-activity and triggers RAS-mediated UC, the second pathway involved in carcinogenesis of low-grade pTa of the bladder $(13,15,21)$. Although we expected to find higher levels of miR-let7c related to single tumors, we believe that a reaction event can explain this fact in multiple tumors, where higher levels of miR-let7c could be produced as an attempt to protect the cell of uncontrolled proliferation.
Despite no statistical differences, we can point some correlations between this miRNA expression profile and the prognostic factors studied. miR-100 was already described as down-regulated involved in low-grade pTa UC carcinogenesis, failing to control FGFR3 expression $(22,23)$. We found a strong miR-100 under-expression in all tumors analyzed, and this finding corroborates to the knowledge of the protective role of miR-100 in this tumor group. Nevertheless, miR-10a showed to be up-regulated in the majority of low-grade pTa UC. miR-10a is linked to cell differentiation and has been reported as under-expressed in high-grade invasive UC (25). High levels of miR-10a could induce neoplastic cell proliferation, but do not alter the key mechanisms of cellular control, such as apoptosis, and it could be involved in non-invasive and well differentiate pTa development $(27,28)$.

\section{CONCLUSIONS}

We did not find differences for miRNA expression profiles associated with prognostic factors in low-grade pTa UC of the bladder. The majority of miRNAs were down-regulated, except miR-10a that is up-regulated in most of cases and seems to have increased expression as tumors present more unfavorable characteristics as multiplicity, larger size and higher rates of recurrence. More studies should be performed in order to find a miRNA profile able to distinguish behavior in low-grade and low-stage bladder cancer to be used in the clinical practice.

\section{CONFLICT OF INTEREST}

None declared.

\section{REFERENCES}

1. Siegel R, Naishadham D, Jemal A: Cancer statistics, 2012. CA Cancer J Clin. 2012; 62: 10-29.

2. McConkey DJ, Lee S, Choi W, Tran M, Majewski T, Lee S, et al.: Molecular genetics of bladder cancer: Emerging mechanisms of tumor initiation and progression. Urol Oncol. 2010; 28: 429-40. 
3. Borden LS Jr, Clark PE, Hall MC: Bladder cancer. Curr Opin Oncol. 2005; 17: 275-80.

4. Soloway MS: The management of superficial bladder cancer. Cancer. 1980; 45: 1856-65.

5. Narayana AS, Loening SA, Slymen DJ, Culp DA: Bladder cancer: factors affecting survival. J Urol. 1983; 130: 56-60.

6. Ali-El-Dein B, Sarhan 0, Hinev A, Ibrahiem el-HI, Nabeeh A, Ghoneim MA: Superficial bladder tumours: analysis of prognostic factors and construction of a predictive index. BJU Int. 2003; 92: 393-9.

7. Botteman MF, Pashos CL, Redaelli A, Laskin B, Hauser R: The health economics of bladder cancer: a comprehensive review of the published literature. Pharmacoeconomics. 2003; 21: 1315-30.

8. Martínez-Torrecuadrada J, Cifuentes G, López-Serra P, Saenz $P$, Martínez A, Casal Jl: Targeting the extracellular domain of fibroblast growth factor receptor 3 with human singlechain Fv antibodies inhibits bladder carcinoma cell line proliferation. Clin Cancer Res. 2005; 11: 6280-90.

9. Castillo-Martin M, Domingo-Domenech J, Karni-Schmidt 0, Matos T, Cordon-Cardo C: Molecular pathways of urothelial development and bladder tumorigenesis. Urol Oncol. 2010; 28: 401-8.

10. Pandith AA, Shah ZA, Siddiqi MA: Oncogenic role of fibroblast growth factor receptor 3 in tumorigenesis of urinary bladder cancer. Urol Oncol. 2013; 31: 398-406.

11. van Rhijn BW, Lurkin I, Radvanyi F, Kirkels WJ, van der Kwast TH, Zwarthoff EC: The fibroblast growth factor receptor 3 (FGFR3) mutation is a strong indicator of superficial bladder cancer with low recurrence rate. Cancer Res. 2001; 61: 1265-8.

12. Bakkar AA, Wallerand $H$, Radvanyi $F$, Lahaye JB, Pissard $S$, Lecerf $L$, et al.: FGFR3 and TP53 gene mutations define two distinct pathways in urothelial cell carcinoma of the bladder. Cancer Res. 2003; 63: 8108-12.

13. Jebar AH, Hurst CD, Tomlinson DC, Johnston C, Taylor CF, Knowles MA: FGFR3 and Ras gene mutations are mutually exclusive genetic events in urothelial cell carcinoma. Oncogene. 2005; 24: 5218-25.

14. Ornitz DM, Xu J, Colvin JS, McEwen DG, MacArthur CA, Coulier F, Gao G, Goldfarb M: Receptor specificity of the fibroblast growth factor family. J Biol Chem. 1996; 271: 15292-7.

15. Zhang ZT, Pak J, Huang HY, Shapiro E, Sun TT, Pellicer A, et al.: Role of Ha-ras activation in superficial papillary pathway of urothelial tumor formation. Oncogene. 2001; 20: 1973-80.

16. Marsit CJ, Houseman EA, Schned AR, Karagas MR, Kelsey KT: Promoter hypermethylation is associated with current smoking, age, gender and survival in bladder cancer. Carcinogenesis. 2007; 28: 1745-51.

17. Enokida $\mathrm{H}$, Nakagawa M: Epigenetics in bladder cancer. Int $\mathrm{J}$ Clin Oncol. 2008; 13: 298-307.
18. Lewis BP, Burge CB, Bartel DP: Conserved seed pairing, often flanked by adenosines, indicates that thousands of human genes are microRNA targets. Cell. 2005; 120: 15-20.

19. Cimmino A, Calin GA, Fabbri M, Iorio MV, Ferracin M, Shimizu M, et al.: miR-15 and miR-16 induce apoptosis by targeting BCL2. Proc Natl Acad Sci U S A. 2005; 102: 139449. Erratum in: Proc Natl Acad Sci U S A. 2006;103: 2464.

20. Lin T, Dong W, Huang J, Pan Q, Fan X, Zhang C, Huang L: MicroRNA-143 as a tumor suppressor for bladder cancer. J Urol. 2009; 181: 1372-80.

21. Johnson SM, Grosshans H, Shingara J, Byrom M, Jarvis $R$, Cheng $A$, et al.: RAS is regulated by the let-7 microRNA family. Cell. 2005; 120: 635-47.

22. Catto JW, Miah S, Owen HC, Bryant H, Myers K, Dudziec E, et al.: Distinct microRNA alterations characterize high- and low-grade bladder cancer. Cancer Res. 2009; 69: 8472-81.

23. Dip N, Reis ST, Timoszczuk LS, Abe DK, Dall'Oglio M, Srougi M, et al.: Under-expression of miR-100 may be a new carcinogenic pathway for low-grade pTa bladder urothelial carcinomas. J Mol Biomark Diagn. 2011: 2: 1-3.

24. Lamm DL, Blumenstein BA, Crissman JD, Montie JE, Gottesman JE, Lowe BA, et al.: Maintenance bacillus Calmette-Guerin immunotherapy for recurrent TA, T1 and carcinoma in situ transitional cell carcinoma of the bladder: a randomized Southwest Oncology Group Study. J Urol. 2000; 163: 1124-9.

25. Dip N, Reis ST, Timoszczuk LS, Viana NI, Piantino CB, Morais $\mathrm{DR}$, et al.: Stage, grade and behavior of bladder urothelial carcinoma defined by the microRNA expression profile. J Urol. 2012; 188: 1951-6.

26. Leite KR, Sousa-Canavez JM, Reis ST, Tomiyama AH, Camara-Lopes LH, Sañudo A, et al.: Change in expression of miR-let7c, miR-100, and miR-218 from high grade localized prostate cancer to metastasis. Urol Oncol. 2011; 29: 265-9.

27. Veerla S, Lindgren D, Kvist A, Frigyesi A, Staaf J, Persson H, et al.: MiRNA expression in urothelial carcinomas: important roles of miR-10a, miR-222, miR-125b, miR-7 and miR-452 for tumor stage and metastasis, and frequent homozygous losses of miR-31. Int J Cancer. 2009; 124: 2236-42.

28. Ørom UA, Nielsen FC, Lund AH: MicroRNA-10a binds the 5'UTR of ribosomal protein mRNAs and enhances their translation. Mol Cell. 2008; 30: 460-71.

Correspondence address:

Nelson Gaspar Dip Júnior, MD

Av. Dr. Arnaldo 455 / 2145

Sao Paulo, SP, 01246-903, Brazil

Fax: +55 11 3061-7183

E-mail: nelson.dip@hotmail.com 